
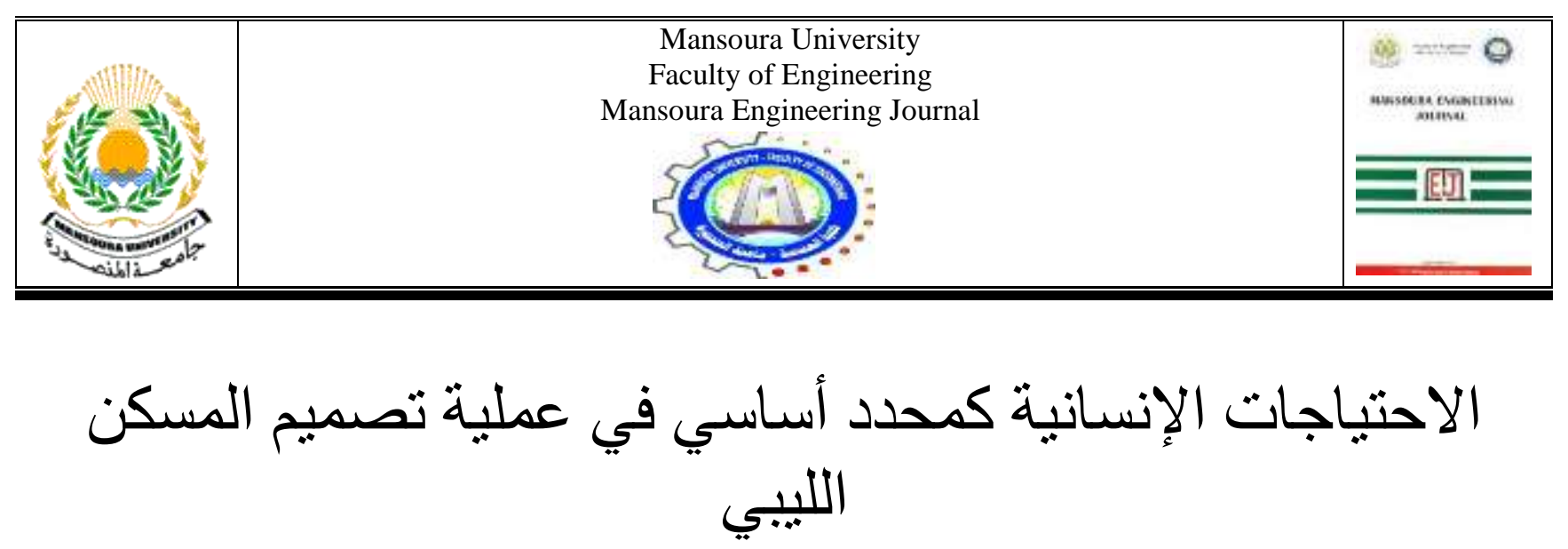

\title{
Humanitarian Needs as a Fundamental Effect On The Design Of The Libyan Dwelling
}

Eng. Adil Hussein Gomaa Elmabrouk, Prof., Abdulraowf Ali Hassan, Prof. Kamal Abdel-Nasser Ahmed and Dr. Mohamed Abdel Wahab Aezzazy

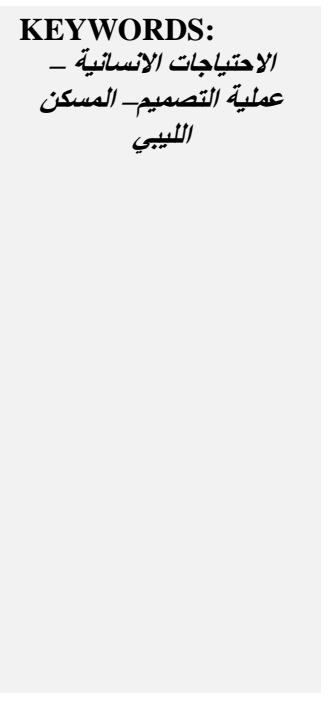

\begin{abstract}
The concept of humanitarian needs is a broad and comprehensive concept, a concept of relative quality associated with dynamic time and space, it must be satisfying the requirements and needs of the individual even feel good and positive behaviors toward pursues its environment and society. Humanitarian needs arising from the constant interaction between internal human motives and method and data environment.

If the basic needs of man is the subsistence level and necessity, but to rise in peace must satisfy other levels, are social and psychological necessities which include security, respect, participation, and other needs.

Humanitarian needs are for users of the most important criteria that must be considered in the design process, but at the same time is one of the toughest such standards, requiring additional time and effort to study social and cultural characteristics of the users, and immaterial nature makes the measure represents extremely difficult.

In this research will examine the concept of humanitarian needs and characteristics and classification requirements associated with the design of housing, in addition to the epidemiology of these needs and focus on the design goals and its relationship to human needs. And then figure out the relationship between human needs and the design process to identify needs for housing design.
\end{abstract}

ووقتًا أضافي لاراسة الخصائص الاجتماعية والثقافية للمستعلين، كما أن طبيعتها الغير المادية تجعل قياسها يمثل صعوبة بالغئة الغئة

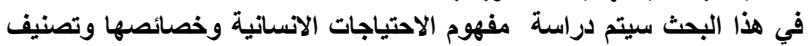

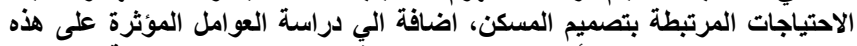

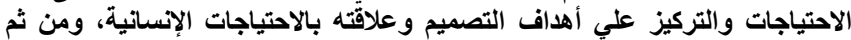

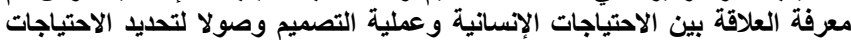
الخاصة بتصميم المسكن الليبي.

\section{- 1}

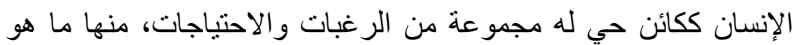

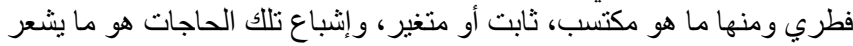

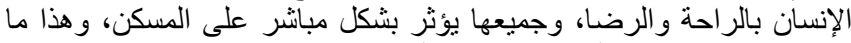

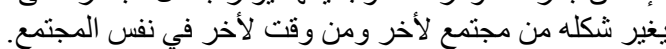

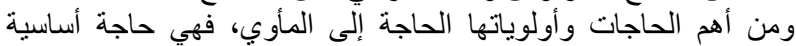

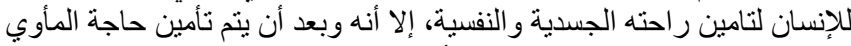

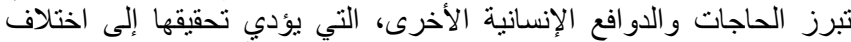

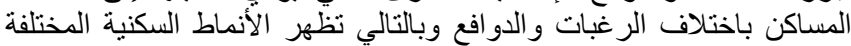

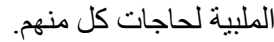

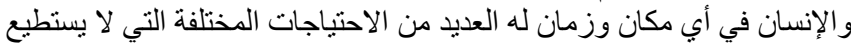

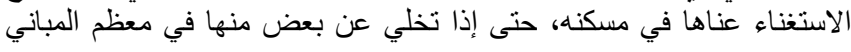

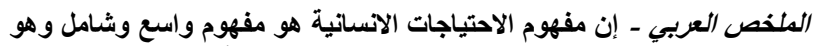

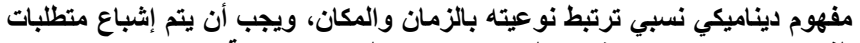

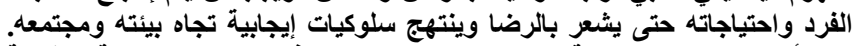

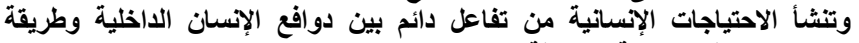
تحقيقها ومعظيات البيئة المحيطة.

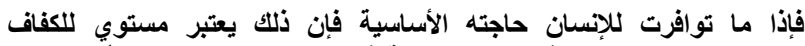

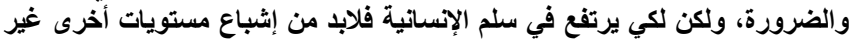

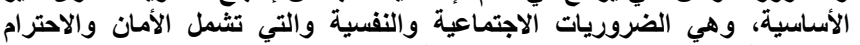
و المشاركة وغير ها من الاحتياجات المختلفة.

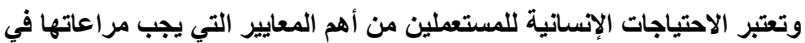

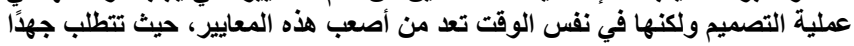

Received:15 January, 2017 - revised: 5 March, 2017- accepted: 13 April, 2017

Eng. Adil Hussein Gomaa Elmabrouk

Prof. Abdulraowf Ali Hassan, Department of Architectural Engineering, Faculty of Engineering, Assiut University

Prof. Kamal Abdel-Nasser Ahmed, Department of Architectural Engineering, Faculty of Engineering, Assiut University

Dr. Mohamed Abdel Wahab Aezzazy, Department of Architectural Engineering, Faculty of Engineering, Assiut University 
- - - متياجات اجتماعية.

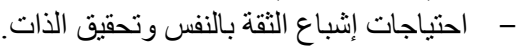
- - اضافة الي ذلك الاحتياجات الاقتصادية.

\section{4- احتياجات الإنسان الثابتة والمتغيرة المؤثرة على تصميم المسكن}

يجب دراسة الاحتياجات الإنسانية التي حددتها أبحاث علماء التحليل

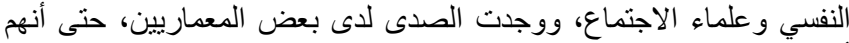

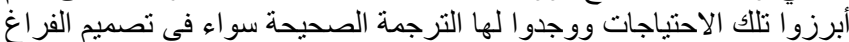

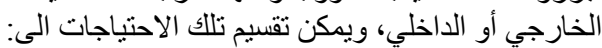

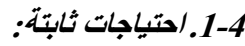

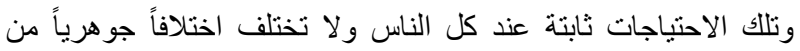

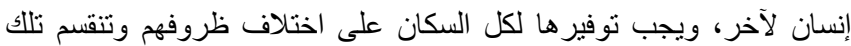

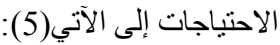

\section{1-1-4} وهي التي ترتبط بالأنشطة الغريزية للإنسان مثل النية (النوم، الأكل، النظافة،

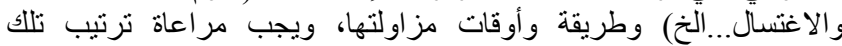

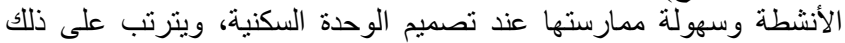

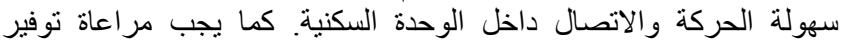

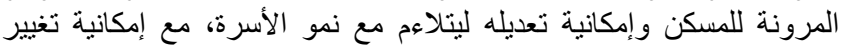

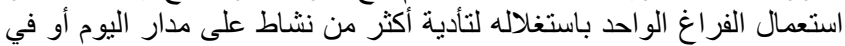

$$
\text { 2-1-4. احتياجات بيولوجية }
$$

فتر ات معينة

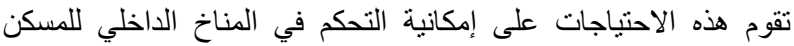

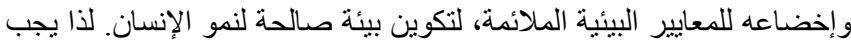

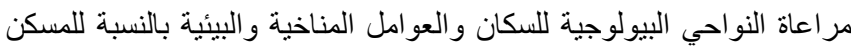
والبيئة المحيطة.

\section{3-1-4}

تختلف الاحتياجات الاجتماعية من مجتمع لآخر تبعاً لاختلاف الظروف

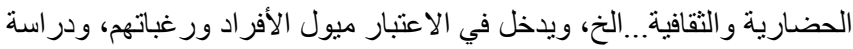

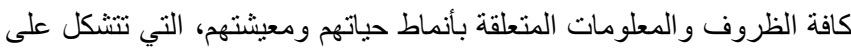

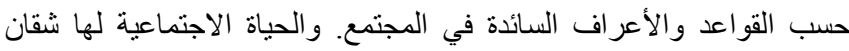

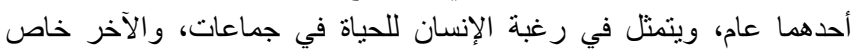

$$
\text { ويتمثل في حفاظ الإنسان على خصوصن وصياته. }
$$

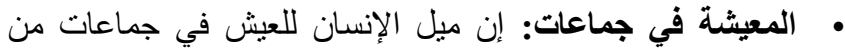

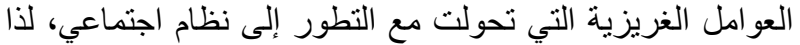

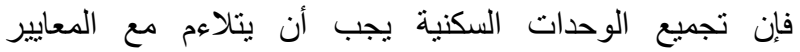

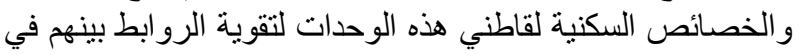

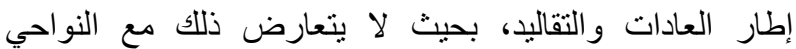
الاجتماعية الأخرى، وهذا يؤثر بطبيعة الحال على لالى العملية

التصميمية(6). • الخصوصية (Privacy): تعتبر الخصوصية من العناصر الهامة

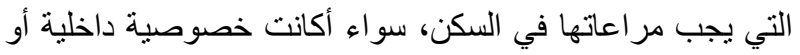
خارجية، في داخل المسكن أو في علاقته بالبيئة المحيطة. 2-4 - 2-4. (حتياجات متغيرة:

تللك الاحتياجات تختلف من إنسان لآخر تبعاً لاختلاف السلوك الإنساني

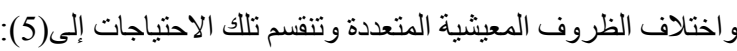

1-2-4. احتياجات وظيفية

وهي التي ترتبط بطريقة أداء وتوزيع الأنشطة الثانوية داخل الوحدة

$$
\text { السكنية وتشمل (قر اعة، تسلية...الخ). }
$$

2-2-4. احتياجات جمالية

يعبر عنها بمقدار الإشباع أو الرضا النسبي طبقاً للشعور بالمتعة والجمال.
الأخرى التي يحتك بها خلال يومه، و لأن المسكن هو بؤرة اهتمام الإنسان، لذا الذا

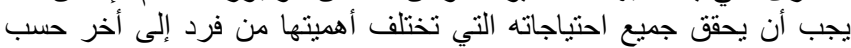

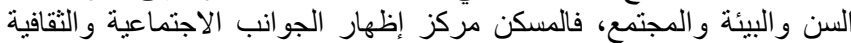
و النفسية المتعلقة بالانشطة الإنسانية.

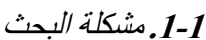

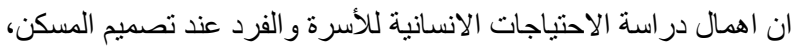

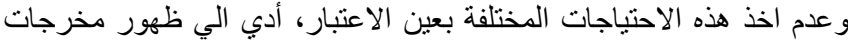

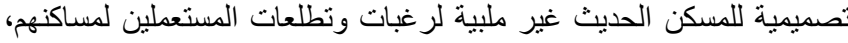

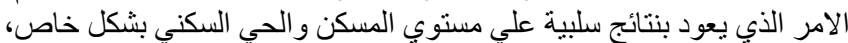

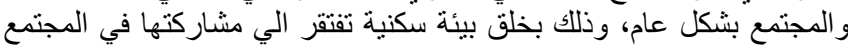

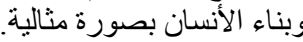

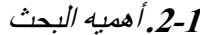

تكمن أهميه هذه الدراسة في إيجاد حلول تصميميه لفراغات إنات المسكن تحقق

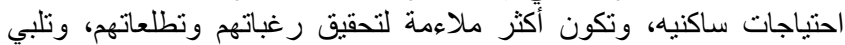

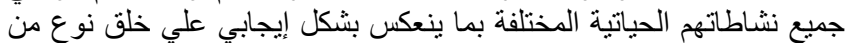

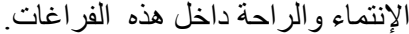

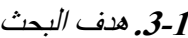

يهذف البحث الي التعرف علي مفهوم الاحتياجات الإنسانية وخصائصها

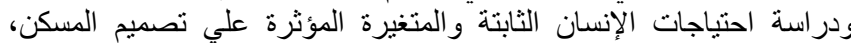

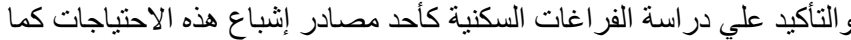
1هدف إلي إيجاد مدخل لتصميم المسكن الملائم الذي يلبي الاحتياجات الانسانية. 4-1

يعتمد البحث علي المنهج الوصفي والتحليلي، بهذف التعرف التهن علي مفهوم

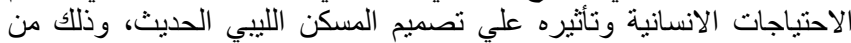

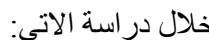
- - التعرف علي مفهوم الاحتياجات الإنسانية وخصائها العوامل المؤثرة عليها.

در اسة احتياجات الإنسان الثابتة والمتغيرة المؤثرة علي تصميم المسكن.

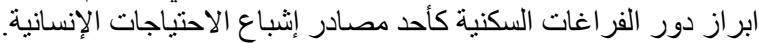
در داسة أهداف التصميم و علاقته بالاحتياجات الإنسانية الإنية.

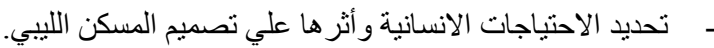
- - الوصول الي خاتمة البحث. -

\section{2- مفهوم الاحتياجات الإنسانية}

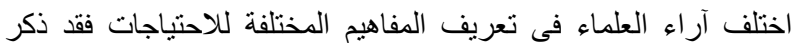

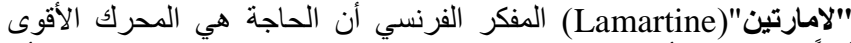

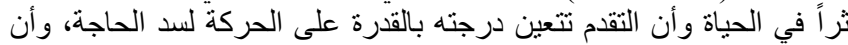

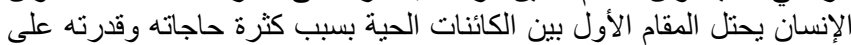

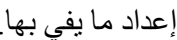

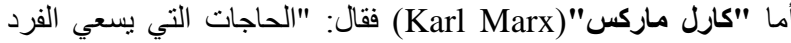

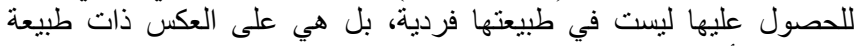

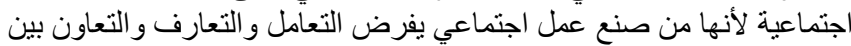

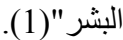
ويمكن تعريف الاحتياج على أنه حالة التغير في البيئة المحيطة بالفرد،

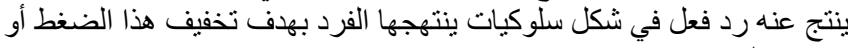
استعادة التوازن(2).

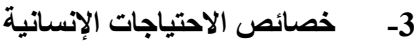

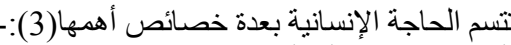

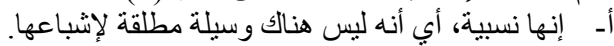

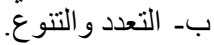

ج- تتميز بقابليتها للإشباع بطريقة مباشرة أو غير مباثرة.

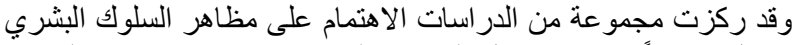

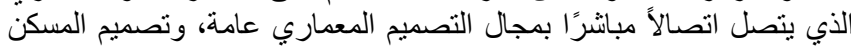

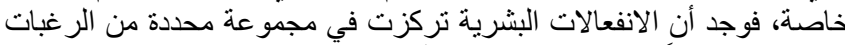

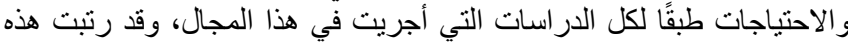

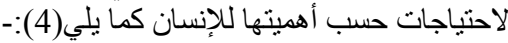
- - الاحتياجات الحيوية المعيشية. - احتياجات الأمن و الأمان. 
لمبدأ السكن، ويعني إحساس الساكن بالأمن من العوامل المحيطة وبالأمن الأنا

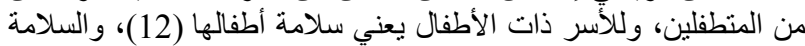

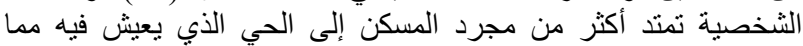

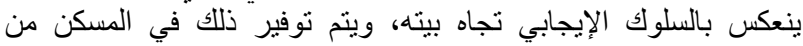

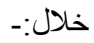

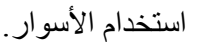
-

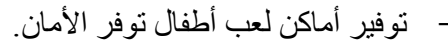

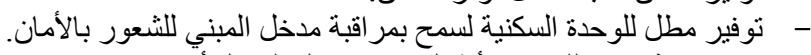

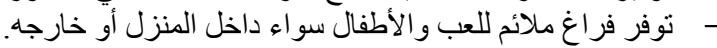

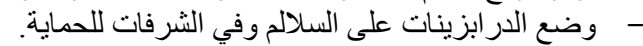
- - توفير طريق هروب عند الحرائق. استخدام مو اد بناء جيدة.

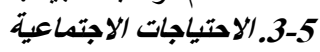

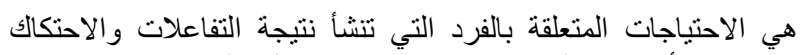

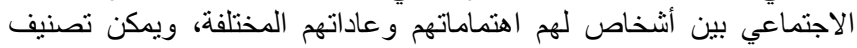

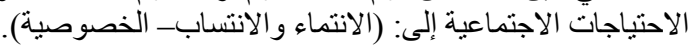

1-3-5. احتياج الانتماء و الانتساب الإنداب

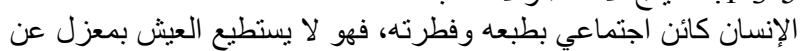

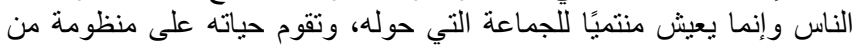

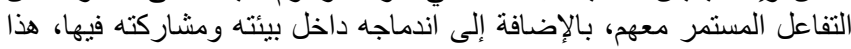

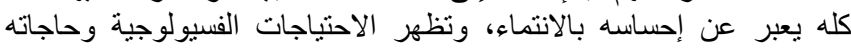

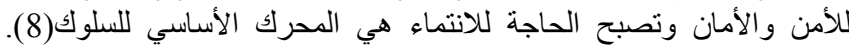

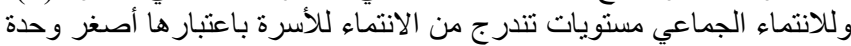

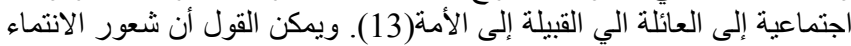

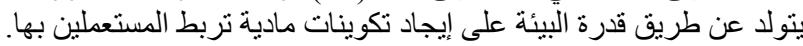

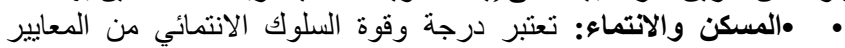

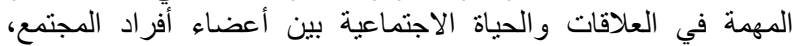

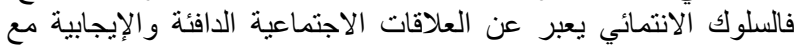

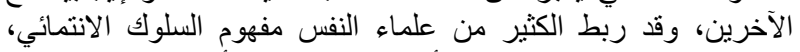
بإرضاء الاحتياجات الإنسانية الأخرى، كالغذاء والفير الأمن و الهوية وتحقيق الانيق

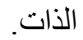
والانتماء يشكل مفردة من مفردات التنمية، فمنظومة التفاعل بين الإنسان الأناء

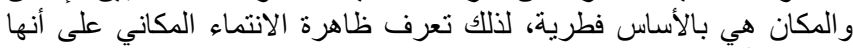

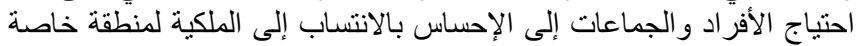

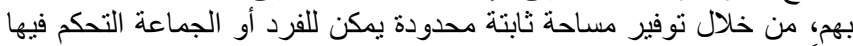

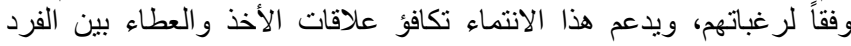
والبيئة الاجتماعية و العمر انية ولئة حوله.

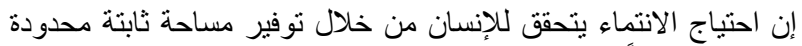

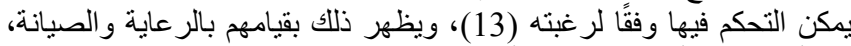

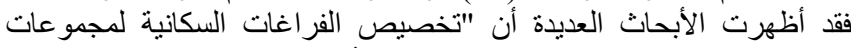

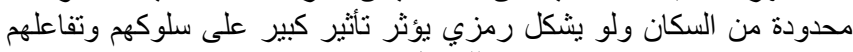

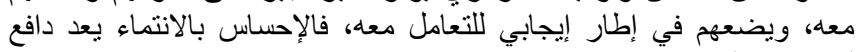

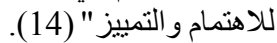

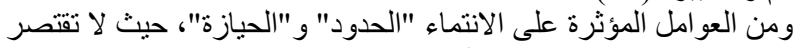

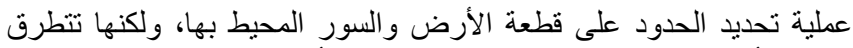

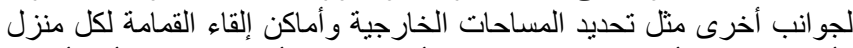

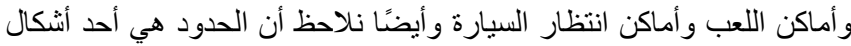

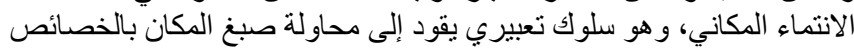
و السمات الثخصية للفرد و والمجتمع. 2-3-5. الخصوصية الندية

الخصوصية هي احتباج إلى تنظيم العلاقات الاجتماعية مع الآخرين لتهيئة

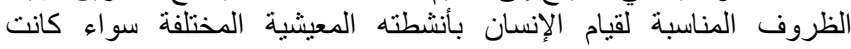

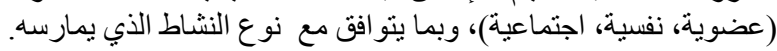

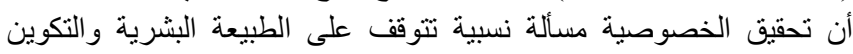

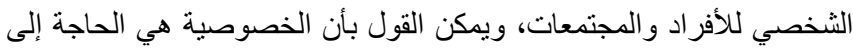

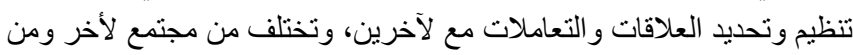

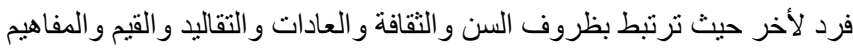

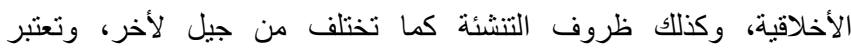

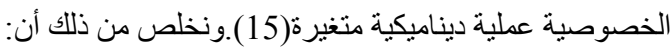
- - الخصوصية هي علاقة اجتماعية بين الثخص و الآخرين.
3-2-4 احتباجات اقتصادية

هي من أهم النواحي المؤثرة على العملية التئية التصميمية، وتنوع الاتجاهات

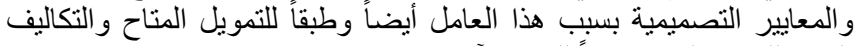
العامة للوحدة السكنية تبعاً للنقاط الآتية:

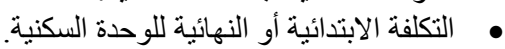
• • • • ما يتعلق بتكاليف المجمو عة السكنية.

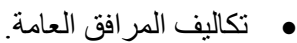

• الحد الأعلى المناسب للكثافة السكانية التي يمكن الوصول إليهام(6).

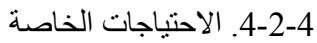
وتثنمل احتياجات ذوي الاحتياجات الخاصة وكبار السن في الاسرة .

\section{5- تصنيف الاحتياجات المرتبطة بالمسكن}

يمكن تصنيف ودمج الاحتياجات للإنسان وخاصة التي ترتبط بالمسكن إلى عدة عناصر رئيسية وهي: تصني:

1-5 الاحتياجات الأساسية

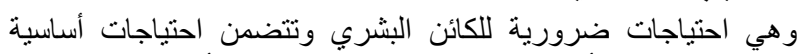

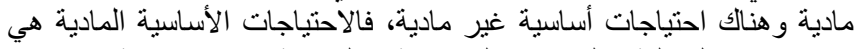

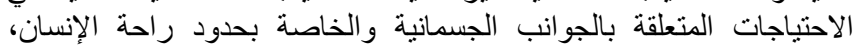

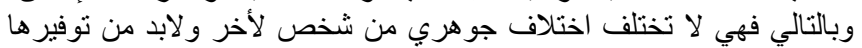

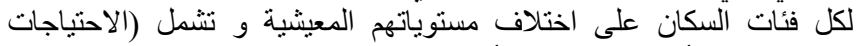

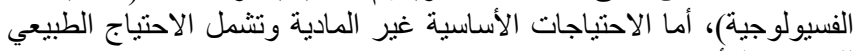

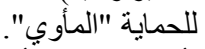

أـ احتباجات أساسية مادية (الاحتياجات الفسيولوجية). ب- احتياجات أساسية غير مادية (الاحتو اء).

تعرف 1-1-5 الاحتياجات الفسيولوجية

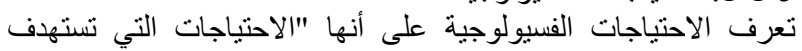

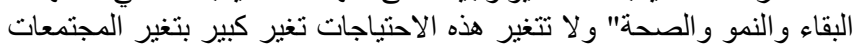

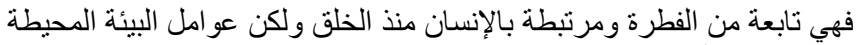

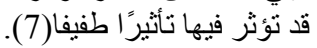

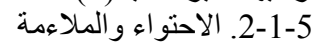

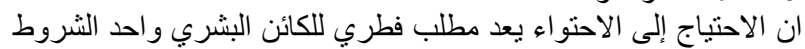

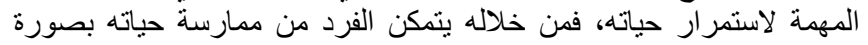

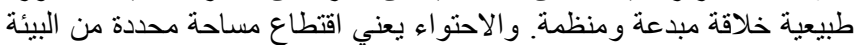

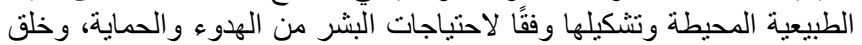

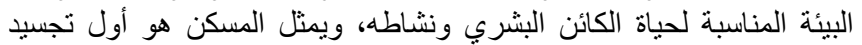
للاحتو اء (بعد رحم الأم)(8).

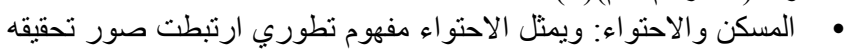

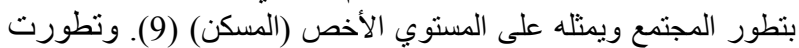

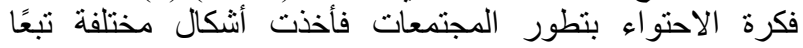

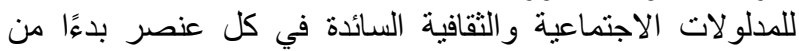

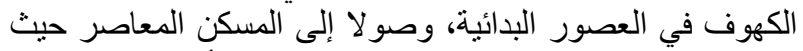

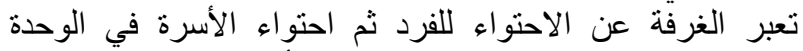

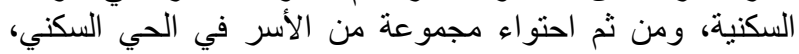

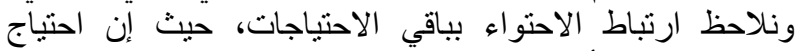

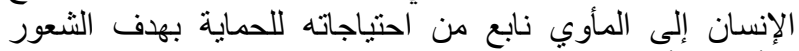

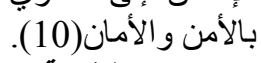
2-5 الاحتياجات النفسية

1-2-5 احتياجات الأمن و الأمان يعد الاحتياج للأمن والأمان من الأن ألامن أهم الاحتياجات الإنسانية والأساسية

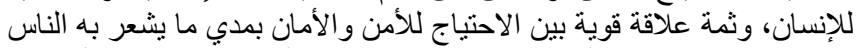

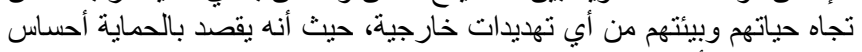

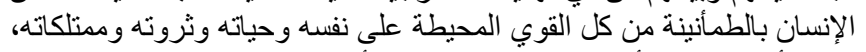

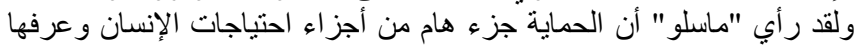

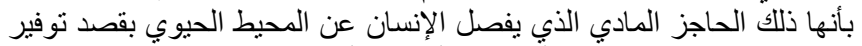

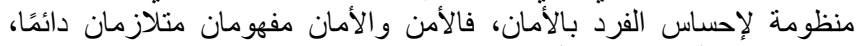
فحين يتوفر الأمن يتحقق الأمان ولكن العكس فالان غير والأمن صحيح(11).

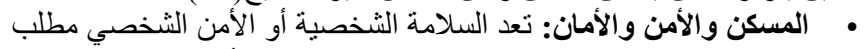
هام للإنسان والرنبة والأني في تحقيق درجة كبيرة من الأمان هو جزء الأه مكمل 


\section{4-5 الاحتياجات المجتمعية}

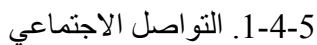

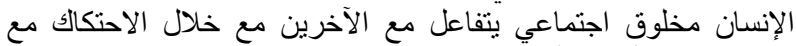

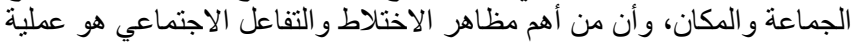

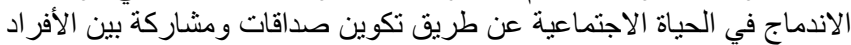

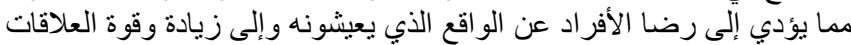

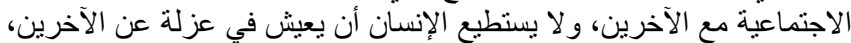
واحتياج الإنسان على الاختلاط تحدده مدي الرغبان الإنبة في التوافق الثقافي الأني

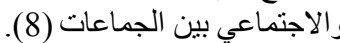
وقد استخدام مفهوم التفاعل والترابط الاجتماعماعي باعتباره سمة تنظيمية

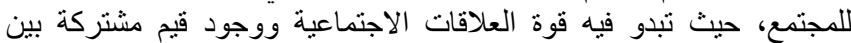

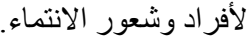

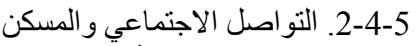

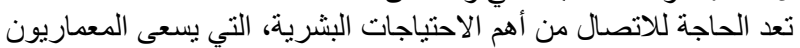

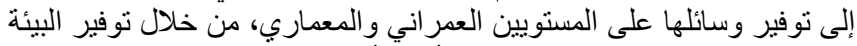

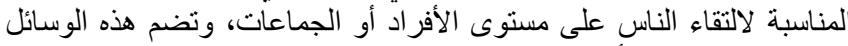

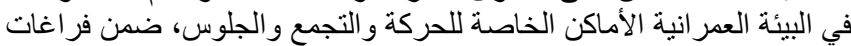

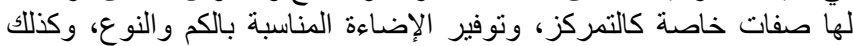

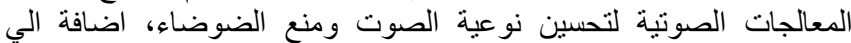

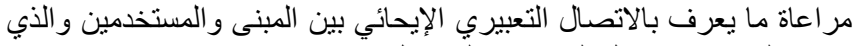

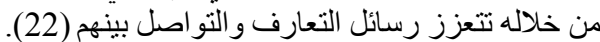

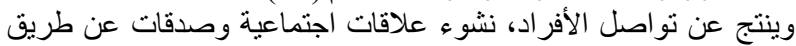
الاتصال في الحيزات المختلفة، أثناء تأدية أنثطة معينة في حيزات التات نصف

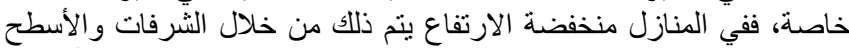

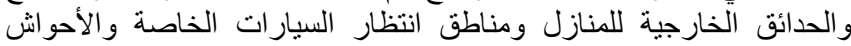

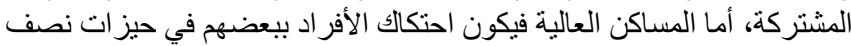

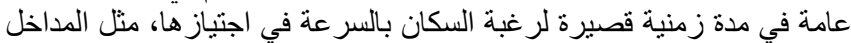

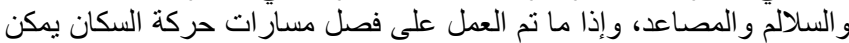

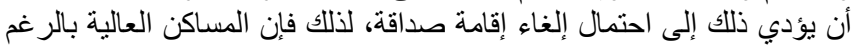

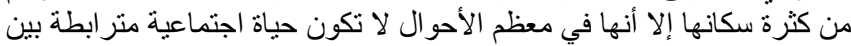

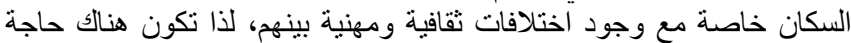
ملحة لمكان اجتماعي محايد من أماكن للالتقاء بين الأفراد دون التقيد بخلفية كل

ونجد أن التصميم الناجح بستطيع أن يحقق فرص لخلق حياة اجتماعية بين ولني

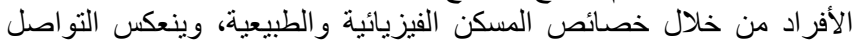

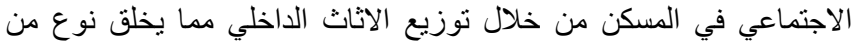

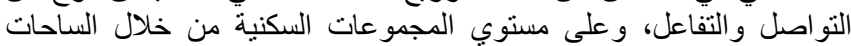

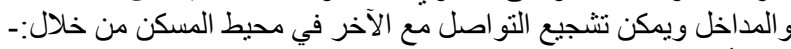
-

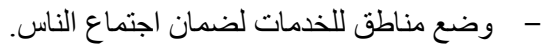
توفر أماكن لعب الأطفال بجوار أماكن صالحة لجاع لجالوس الكبار يوفر إمكانية تكوين صداقات والمشاركة في مر اقبة الأطفال. 5-5. - 5. احتياجات التعبير و هي الاحتياجات التي لا يمكن وضع معايير محددة لقيامها وتثمل:

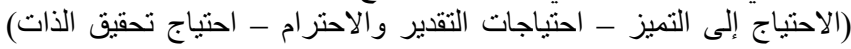
وهذه الاحتياجات متثابكة مع بعضها لإئل يمكن فصل احتياج من احتياجات

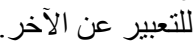

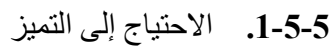

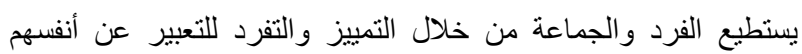

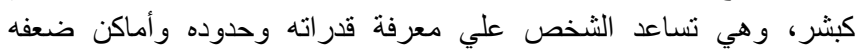

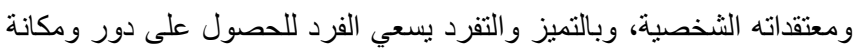

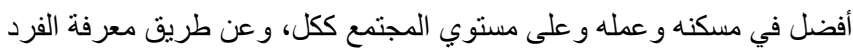

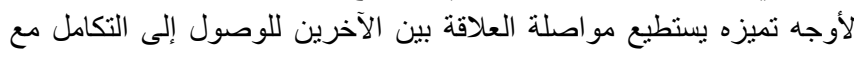

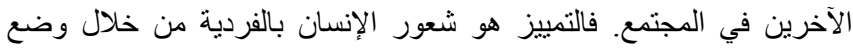

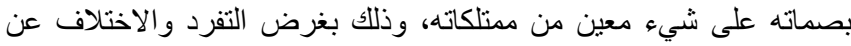
الأخر ويظهر ذلك بصورة واضحة في المسكن (23).
- الخصوصية هي علاقة مع عناصر البيئة يتم من خلالها اكتساب العلاقات

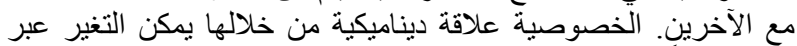

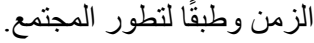

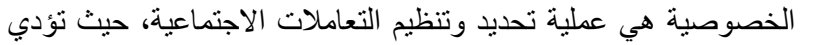

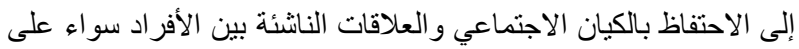

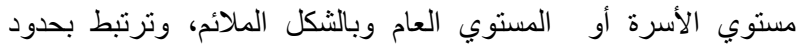

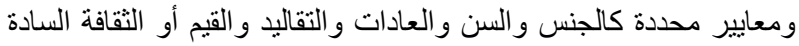

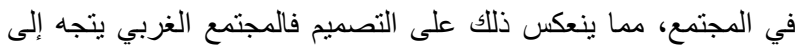

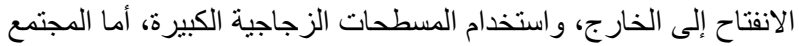

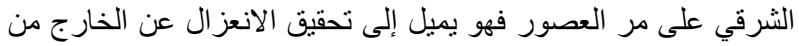

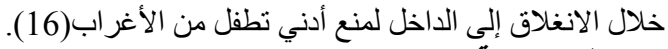

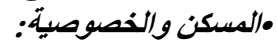

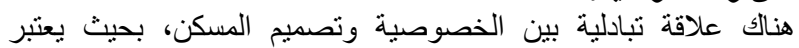

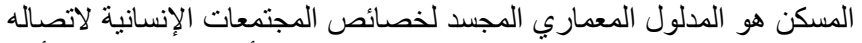

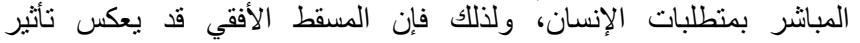

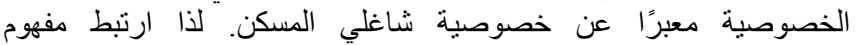

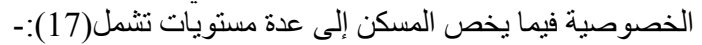
أ - خصوصية داخلية:

و هي الخصوصية التي يجب تو افرها داخل الوحدة السكنية، وتتمثل في الإني

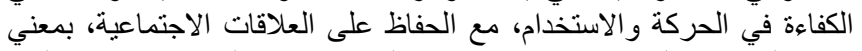

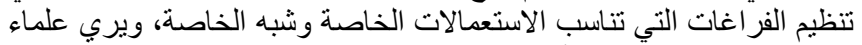

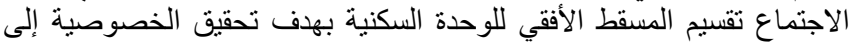

$$
\text { منطقة عامة (مدخل السكن) }
$$

$$
\begin{aligned}
& \text { - منطقة نصف عامة (ملنة (الصنالون - الطعام - المطبخ - غرفة نوم وحمام } \\
& \text { الضيوف). } \\
& \text { - منطقة خاصة (غرفة نوم الأو لاد و الحمام الخاص بها) }
\end{aligned}
$$

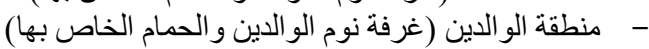

$$
\begin{aligned}
& \text { ب ب - خصوصية خارجية : }
\end{aligned}
$$

1 - الخصوصية البصرية:

وتعني في مضدونها البهرية الحماية الكاملة من نظرات المنطفلين وذلك فيما

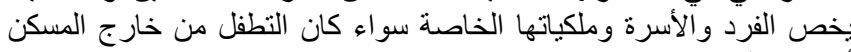

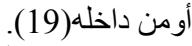
ولا تعني الخصوصية البصرية فصل عنصر عن أخر أو فصل البيئة

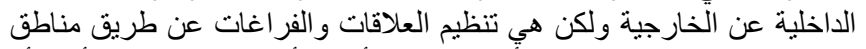

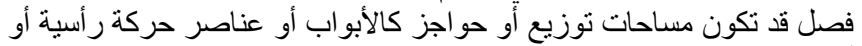
أفقية(20).

2 - 2 الخصوصية السمعية:

تختص بتوفير بيئة صوتية مناسبة سواء على الته مستوي السكن أو خارجها

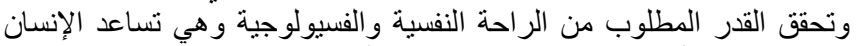

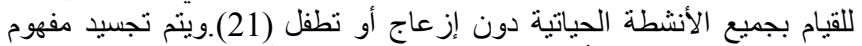

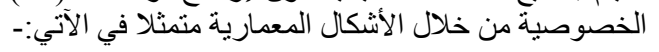

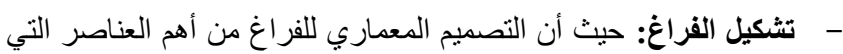
يستطيع من خلالها المصدم تلبية الاحتياجات الإنسانية المطلوبة المبة للإنسان.

تصميم العناصر معمارية: هناك بعض العناصر التي تساعد على تحقيق

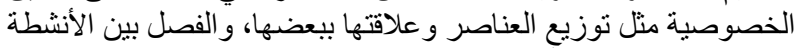

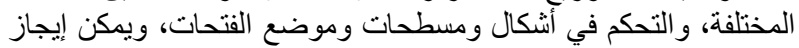

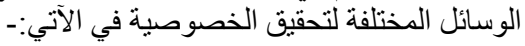
فصل غرفة نوم الو الدين عن فر اغات المسكن.

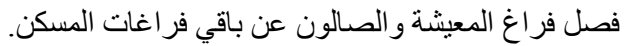

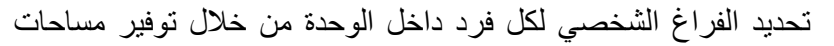
مناسبة. تحديد الفر اغات الملائمة لكل وحدة سكنية.

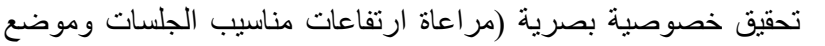

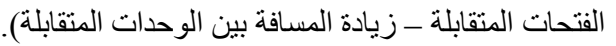

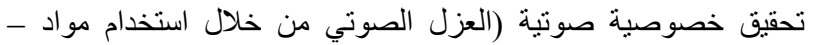

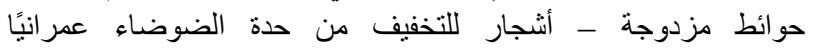
وسيكولوجيًا - مر اعاة المسافات الكافية بين الوحدات السكنية.) (18). 
سكنية بل إلى إسكان يحقق تطلعاتهم الأفضل، ويحتاجون المشاركة الفعلية في بناء مساكنهم.

فالإنسان بطبعه مخلوق اجتماعي يشترك بعدة علاقات اجتماعية مع العديد

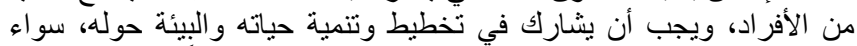

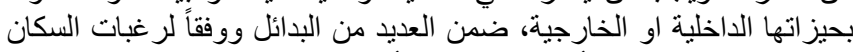

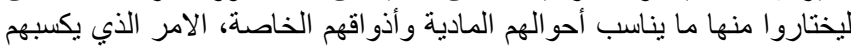

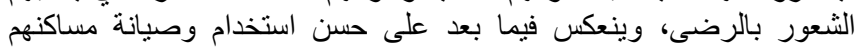
وتحسينها(24).

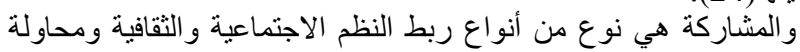

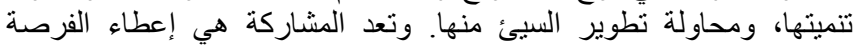

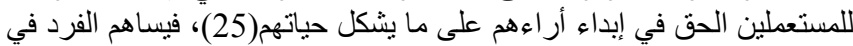

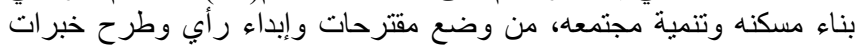

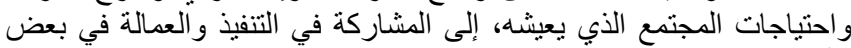

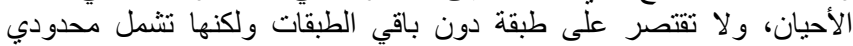

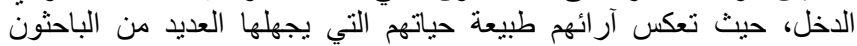

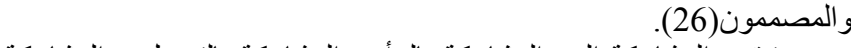
وتنقسم المشاركة إلى: المشاركة بالر أب، المشاركة بالتمويل، و المشاركة

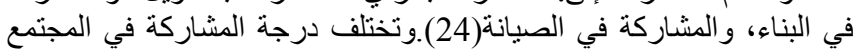

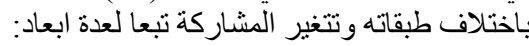

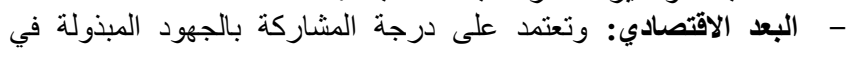

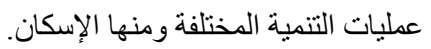

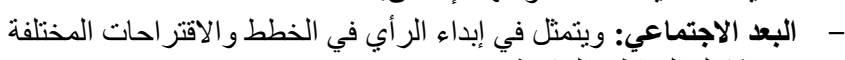
في تشكيل المناطق السئم ويتية.

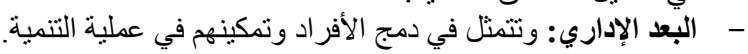

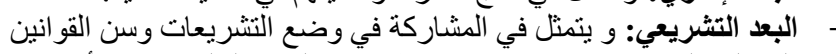

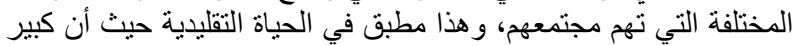

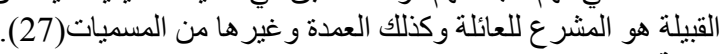

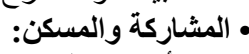

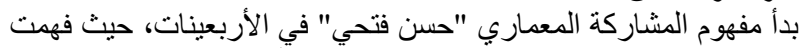

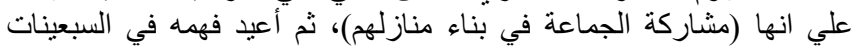

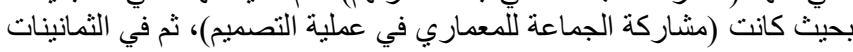

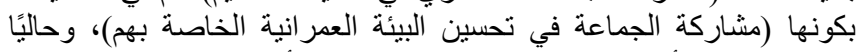

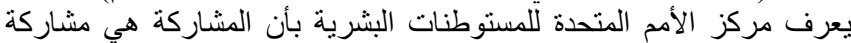

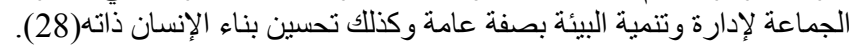

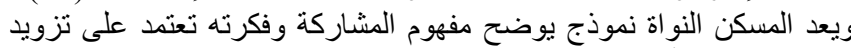

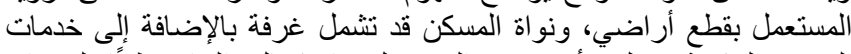

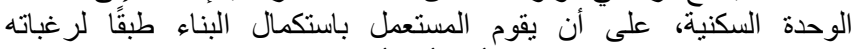
و احتياجاته وقدر اته سو اء تدريجيًا أفقيا أو رأسيًا.

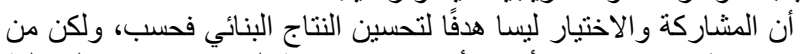

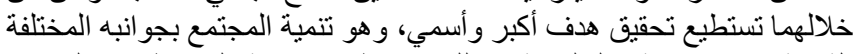

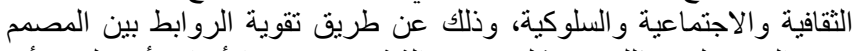

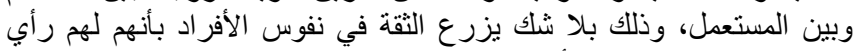

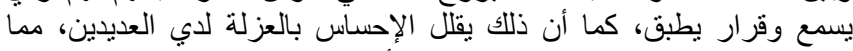
يساعد في تتمية السلوكيات الإيجابية لاي الأفر اد تلجاه المجنمع.

\section{6- العوامل المؤثرة على الاحتياجات الإنسانية}

سعي المعماريون إلى إثباع الاهتمامات الجديدة والتي تدور حول العلاقة

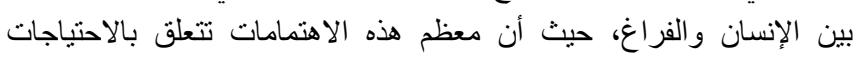

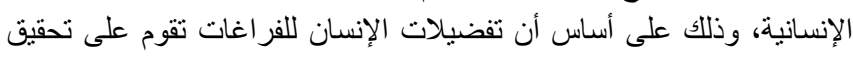

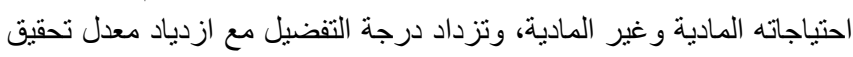

لاحتياجات.

غير انه من الصعب التسليم بأن الحاجات الأساسية للفرد و التي تشمل

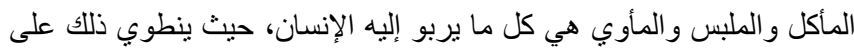

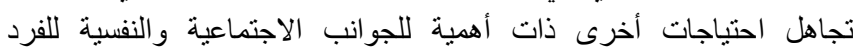

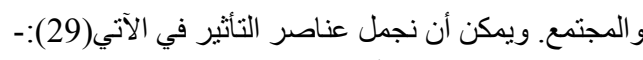

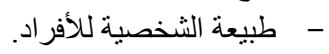

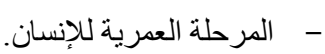

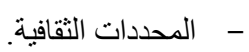

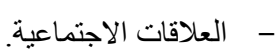

2-5-5

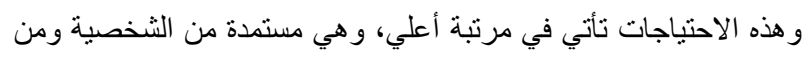

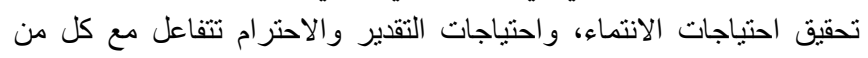

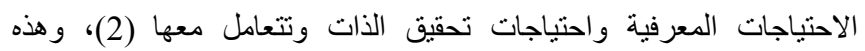

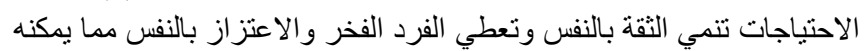
من اتخاذ القرارات بحكمة. 3-5-5 احتياجات تحقيق الذات:

تعتبر احتياجات تحقق الذات من أهم الاحتياجات للات الإنسان التي تظهر جليًا

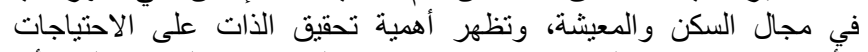

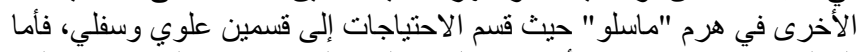

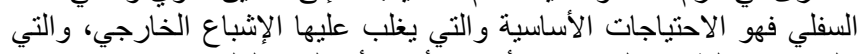

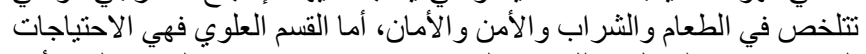

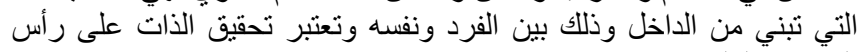
الحاّجات العلوية. وتعتبر الذات جوهر وأصلة وأصل الثخصية الإنسانية وهي الأساس في توجيه

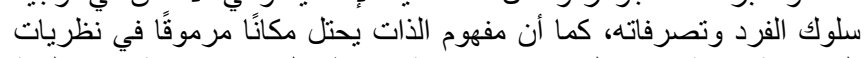

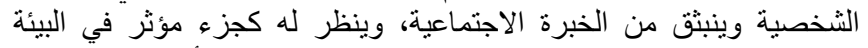

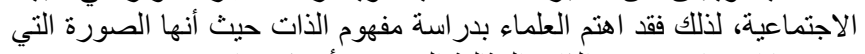

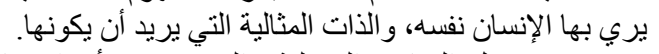

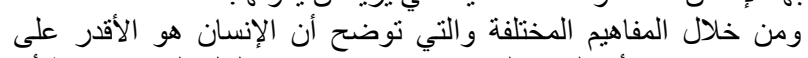

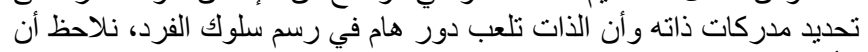

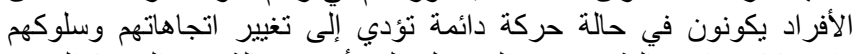

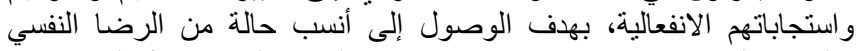

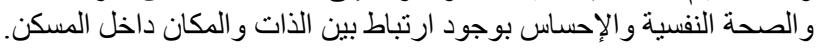

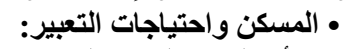

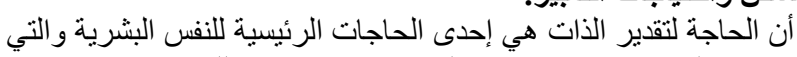

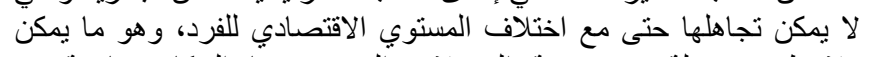

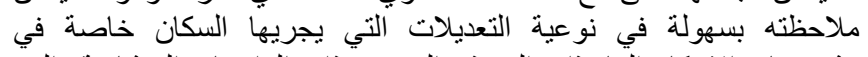

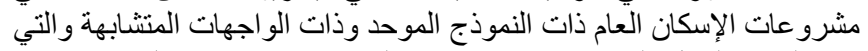

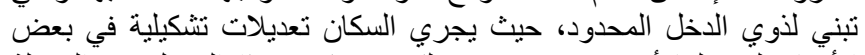

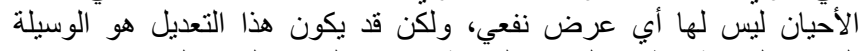

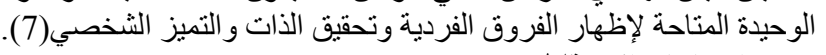
6-5. - احتياجات الاستقلال:

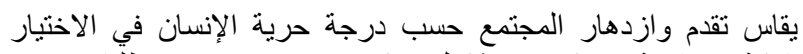

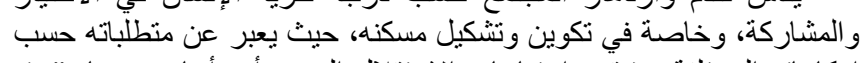

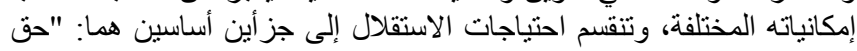
الاختيار ، وحق المشاركة".

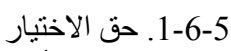

الاختيار هو من أهم الاحتياجات للإنسان، فهو أن يملك الفرد حق الإنتيار

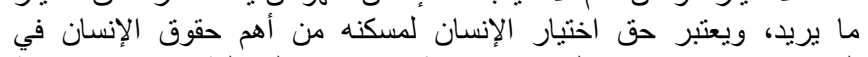

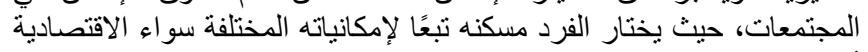

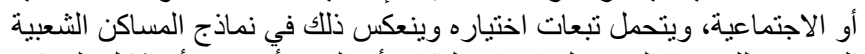

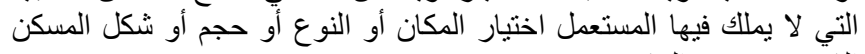

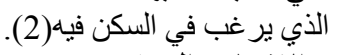

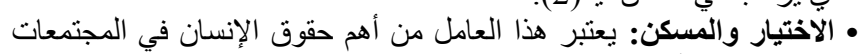

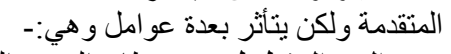

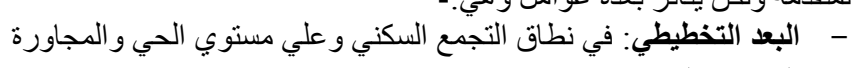
السكنية و المدينة.

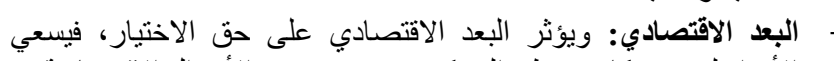

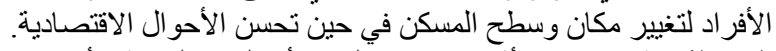

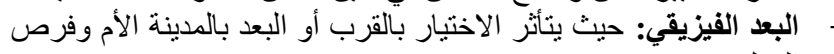

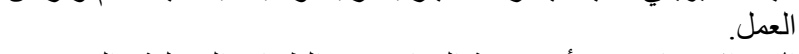
البعد الاجتماعي: ويأتي نتيجة التجانس مع الطبقات المختلفة والقرب من

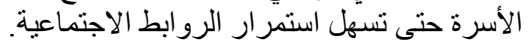

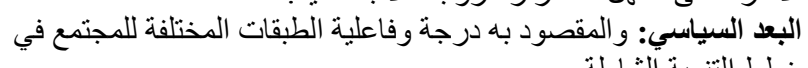
خطط التنمية الثناملة.

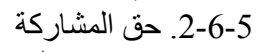
يمكن تعريف دور المشاركة في تطوير المدينة بأنه إثر الك السكان في بناء

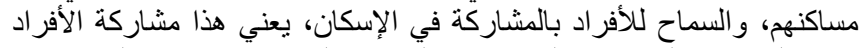

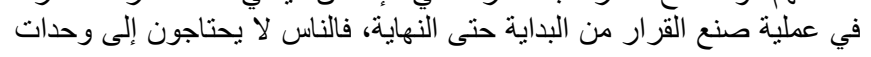




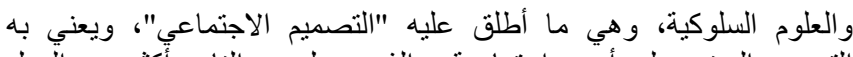

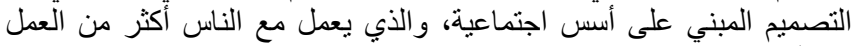

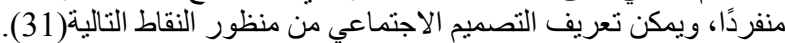

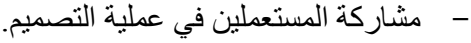
توجيهرم لكيفية استخدام المبني بطريقة والئية واعية للوصول إلى إلى التو افق بينهم.

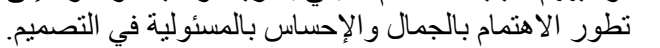

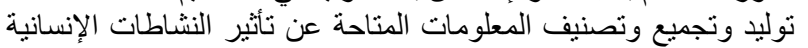

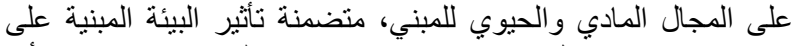

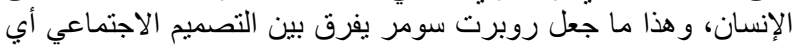

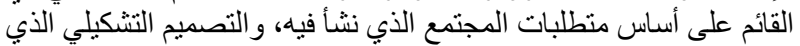

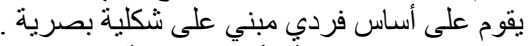
2-8

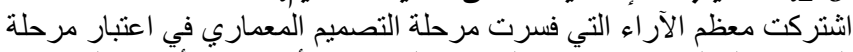

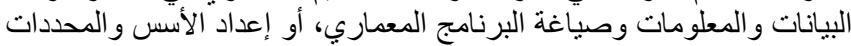

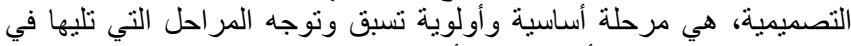

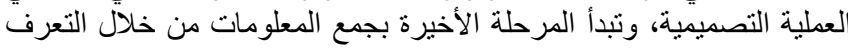

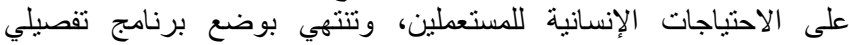

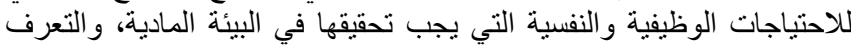

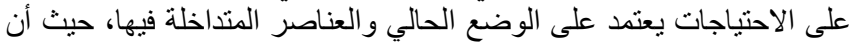

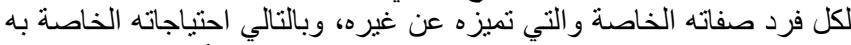

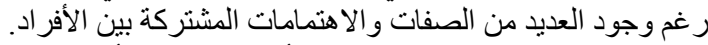

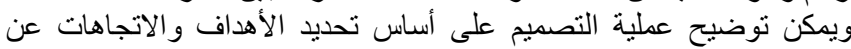
طريق(30):1- التعرف على الاحتياجات الإنسانية و المتطلبات للمستعملين.

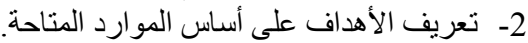

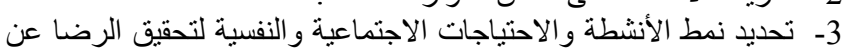
المنتج النهائي.

4- تحديد العلاقة بين المتطلبات الإنسانية والبيئة المبنية كسبيل لاستيفاء ما يربط بينهما.

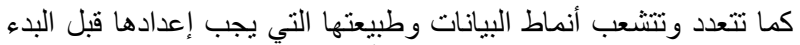

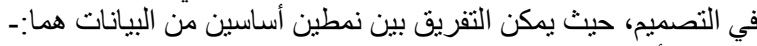

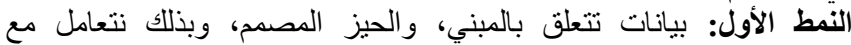

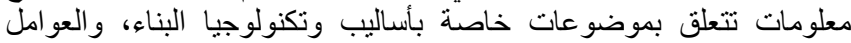

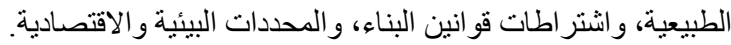

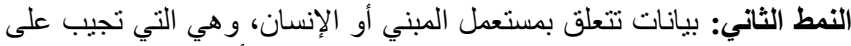

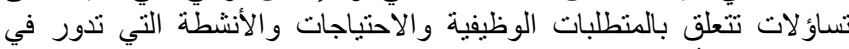

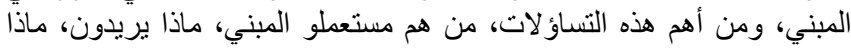
يفعلون وكيف، ومن أهم هي احتياجاتهم بالتحديد؟ هن

\section{9- تحديد الاحتياجات وتصميم المسكن الليبي}

يتركز احتباج الأسرة من عناصر المسكن في مجموعة من المكونات الأساسية

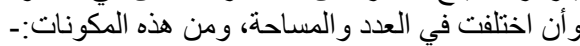
أ- الحيز المعيشي: ويشمل أماكن معيشة الأسرة، وممارسة الماتهة الهوايات

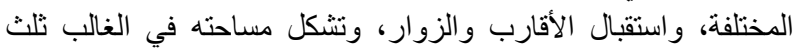

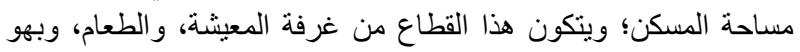

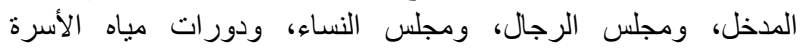
والضيوف، وقد يمند هذا القطاع إلى خارج حدود المبني ليشمل الئل الأفنية و الشرفات الخارجية.

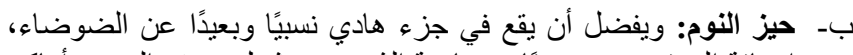

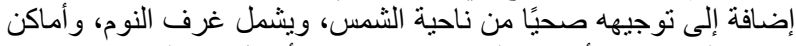

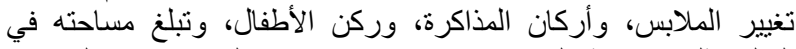

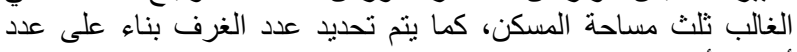

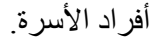
ج- حيز الخدمات: ويشمل باقي العناصر من مطبخ، وحمامات ودور وات مياه

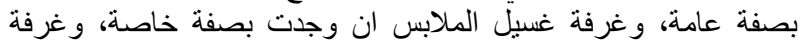

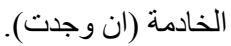

1-9 رصد التغير الحاصل في العناصر والفراغات المكونة للمسكن اللبيبي

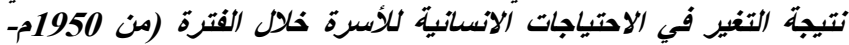
منهج التحليل المتبع في البحث كان كلاتي :
ويجب أن تكون الاحتياجات الإنسانية أكثر تنوعًا وثراء، وذللك بإيجاد

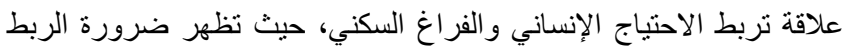

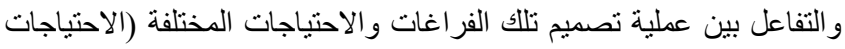

المعيشية والاجتماعية و النفسية).

7- الفراغات السكنية كأحد مصادر إثباع الاحتياجات الإنسانية

تعتبر العلاقة بين الإنسان و الفراغات السكنية من القضايا التي شغلت

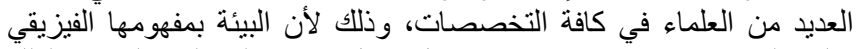

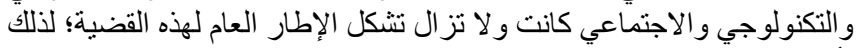

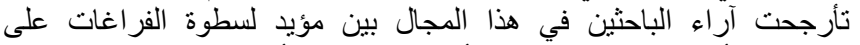

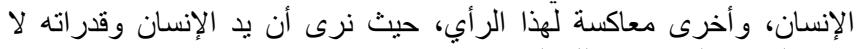
حدود لها في التحكم في تللك الفر اغات لهذات.

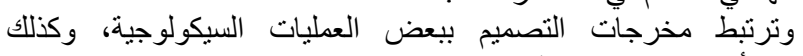
بمدخلات أخرى عديدة خاصة لاحتباجات الإنسان.

1-7. الخصائص المادية للفراغات السكنية(الصيازة السكنية):

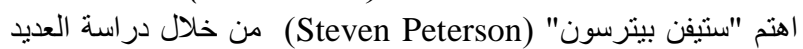

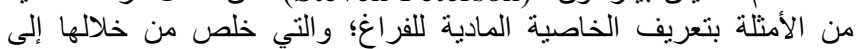

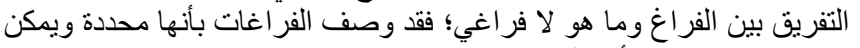

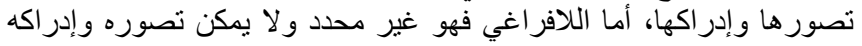
وتحديد حجمها.

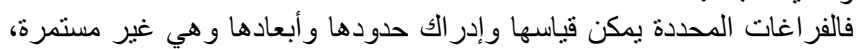

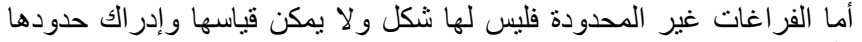
و أبعادها، و هي غير مستمرة.

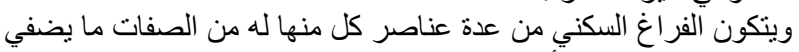

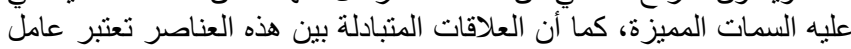

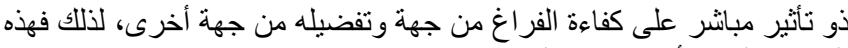

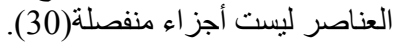

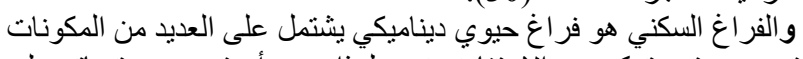

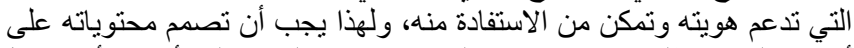

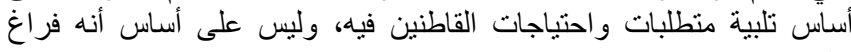

\section{أهداف التصميم وعلاقته بالاحتياجات الإنسانية}

\section{$\mathbf{- 8}$}

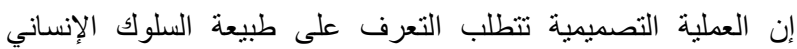

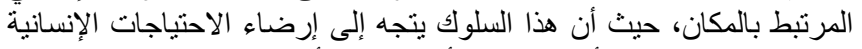

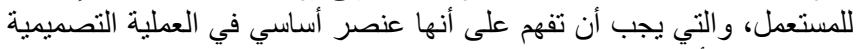
للفر اغات من أجلّ الإنسان.

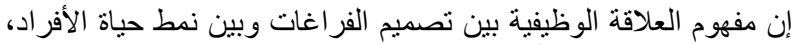

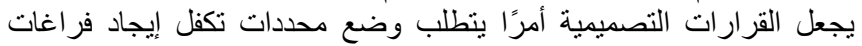

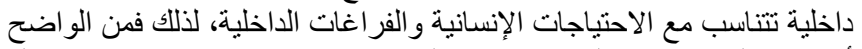

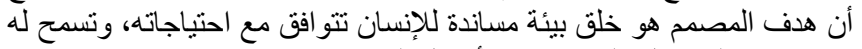

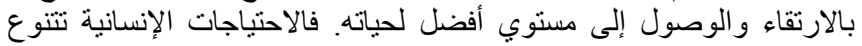

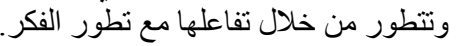

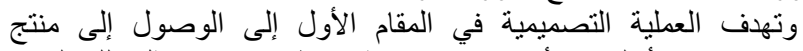

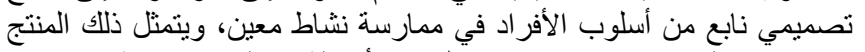

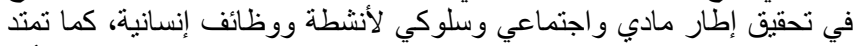

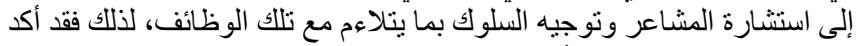

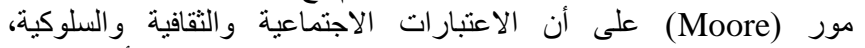

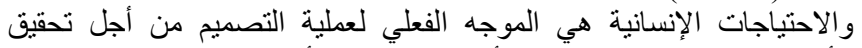

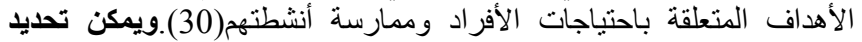
ثلاثة أهداف أساسية للتصميم هي:-

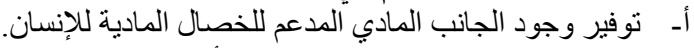
بـ تحقيق المواضع السلوكية الضرورية الضية للأنشطة.

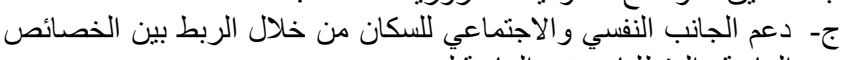
المادية و المنطلبات غير المادية لَه.

1-8 الاحتياجات الإنسانية والتصميم الاجتماعي للمسكن:

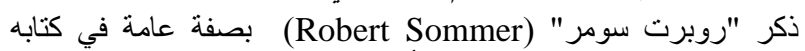
التصميم الاجتماعي، والذي تناول فيه أبعاد العلاقة بين التصميم المعماري 


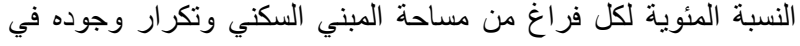

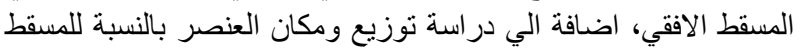

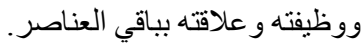

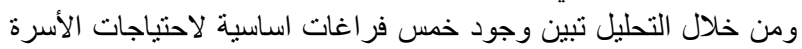

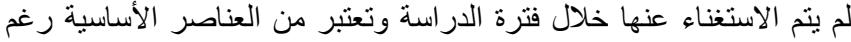

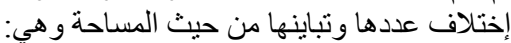

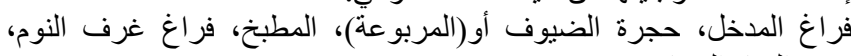
دورة المياه(الحمام).

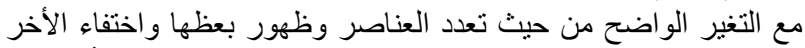

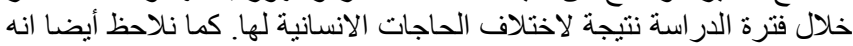

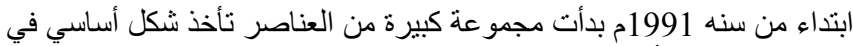

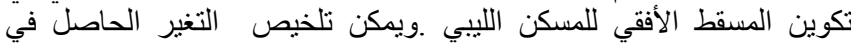

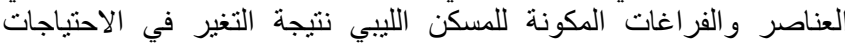
الانسانية للأسرة بالجدول رقم(1) العكرنة

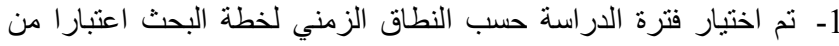

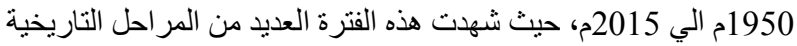

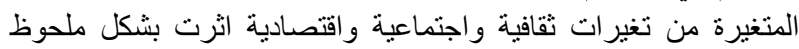

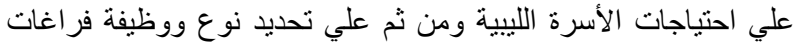

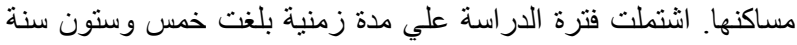

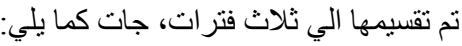

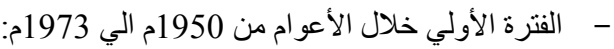

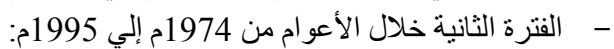

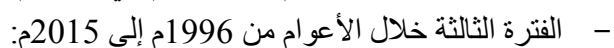

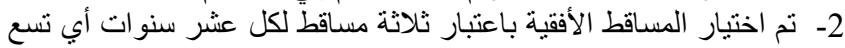

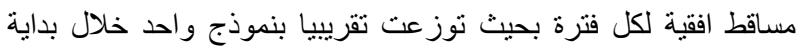
العشر سنو ات ومنتصفها ونهايتها. 3- تم التحليل من خلال دراسة المساقط وحساب مساحاتها، ودراسة مساحة

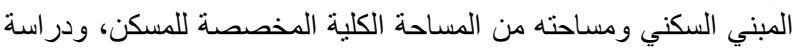

\begin{tabular}{|c|c|}
\hline & 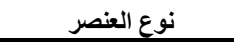 \\
\hline أستمر وجنود فر الدر المدخل خلال هذه الفترة واختفي خلال سنه 2002م نظر الدمجة في بيت الدرج لتوفير مساحة المدخل و إضافته الي & مدخل \\
\hline 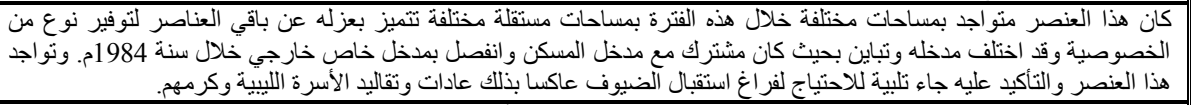 & حجرة ضيوف (مربوعة) \\
\hline لم يظهر هذا العنصر الإخلال عام 1981م لتلبية احتياج الضيوف وراحتهم. وأرتبط بالمربو عه بشكل خاص. & دورة مياه للضيوف \\
\hline 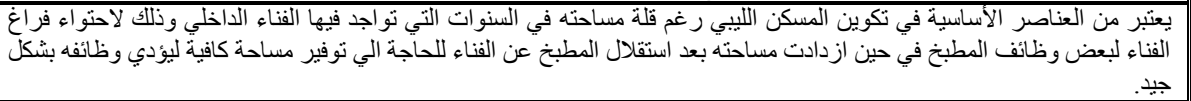 & مطبخ \\
\hline 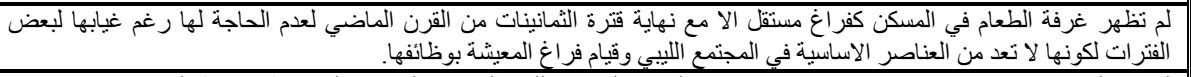 & غرفة طعام \\
\hline 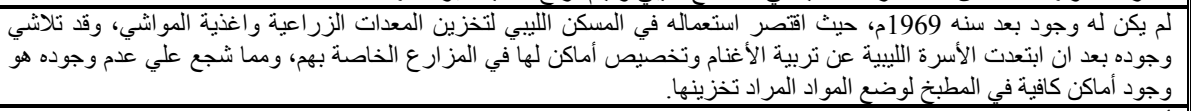 & 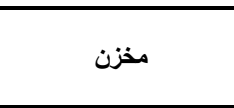 \\
\hline 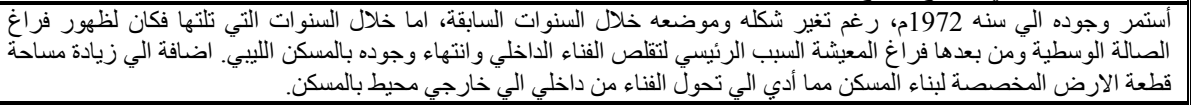 & فناء داخلي \\
\hline 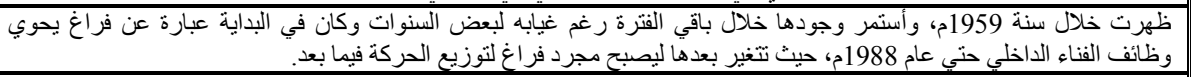 & صالة وسطية \\
\hline 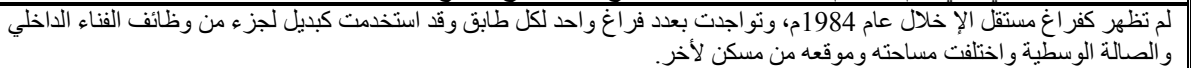 & 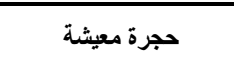 \\
\hline لم تظهر حتي عام 1978م، واستخدت كفر اغ لتامين الاطلالة نحو الحديقة الخارجية واصبح من السمات الأساسية للمسكن الليبي & الثرفات (بلكونة) \\
\hline 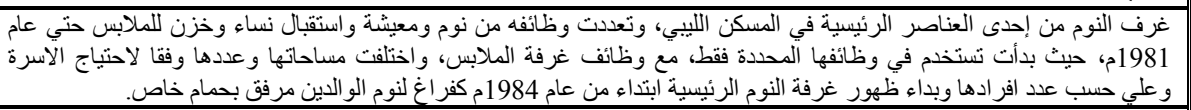 & حجرة نوم \\
\hline 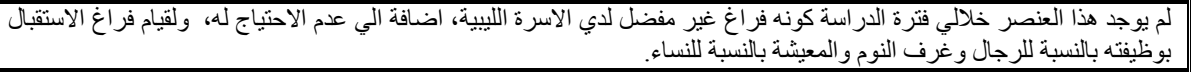 & غرفة نوم ضيوف \\
\hline 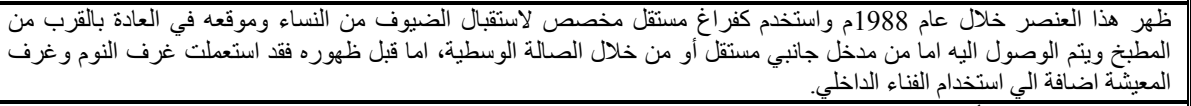 & 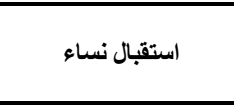 \\
\hline 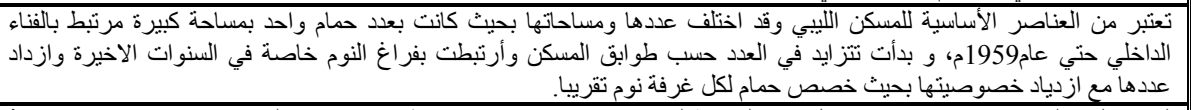 & دوره مياه خاصة \\
\hline 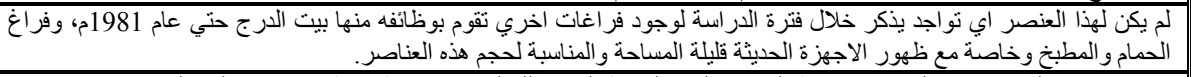 & 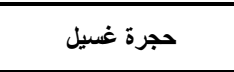 \\
\hline 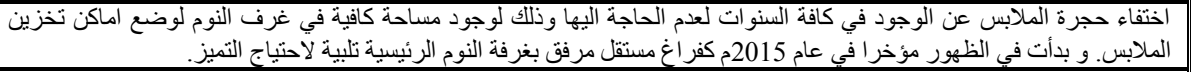 & 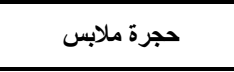 \\
\hline 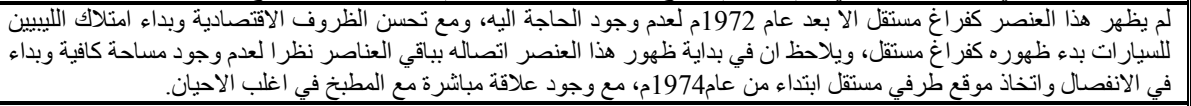 & جراج \\
\hline 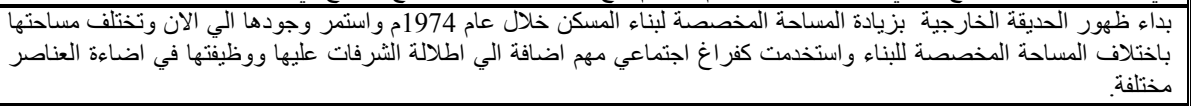 & حديقة خارجية \\
\hline 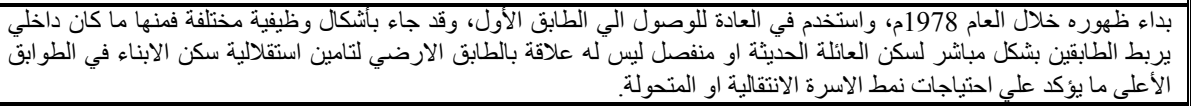 & بيت الارج \\
\hline 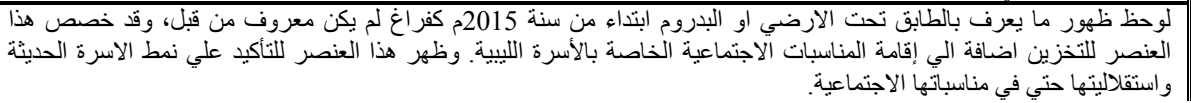 & 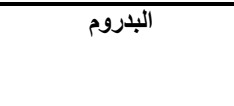 \\
\hline
\end{tabular}

عام و الأنسان بشكل خاص قابلها اختفاء لبعض الفراغات وقيام فر اغات أخري

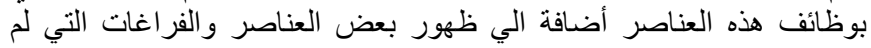

ان التغير الحاصل في العناصر المكونة للمسكن الليبي أتضح من خلال

ظهور لبعض الفراغات لم تكن معروفة من قبل لتلبية احتياجات الأسرة بشكل 
أـ الحصول على مسكن بمساحة مناسبة للاحتياجات الفعلية للأسرة، فلا

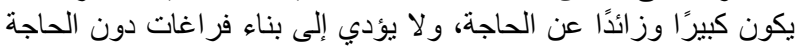
لها، أو أقل من احتياجاه فيؤدي على على عدم راحة الأسرة.

بـ تفادي ظهور أخطاء ما بعد تنفيذ المسكن والإقامة فيه، والتي تستدعي إجر اء التعديلات على المسكن.

تـ أهمية تحقيق المسكن لاحتباجات مستعمليه، امر في غاية الاهمية حيث إهبث

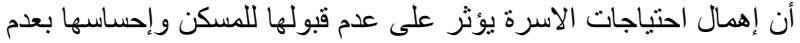

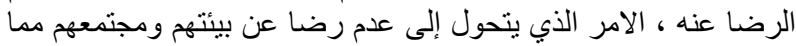
يولد سلوكيات غير إيجابية تجاه المجتمع.

ويظهر من تصميم المساكن الحديثة تو اجد العديد من العناصر و الهدر في ولئي

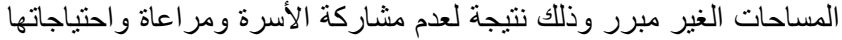

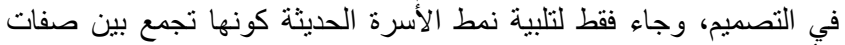

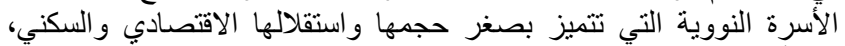

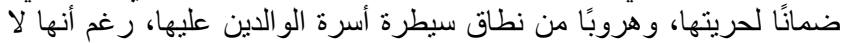

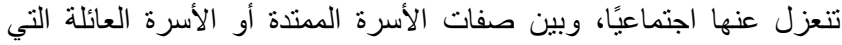

تتميز بعلاقات اجتماعية خاصة.

\section{المراجع والمصادر:}

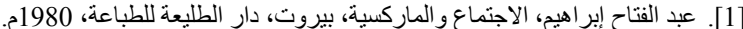
[2]. 1 - اناهيد ماهر واكئ، الاحن، الاعتبارات الإنسانية كمدخل لتصميم المسكن الملائم، رسالة دكتور اه، جامعة القاهرة ، 2007م.

[3]. Brenda dubsia and Karla k, mibey: social work an empovering profession (boston, allyn and bacom), 1992.

[4]. هبة اله أحمد بسيوني، المسكن المعاصر بين المنطلبات المادية والاحتياجات الإنسانية ،

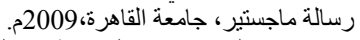

[5]. ياسر سعيد الكفراوي، اساليب تطوير المسكن تصميميا لمواجهة تغير احتياجات السكان،

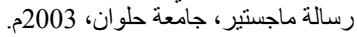

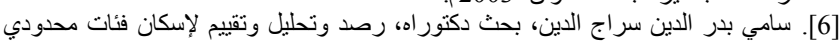

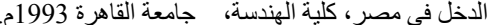

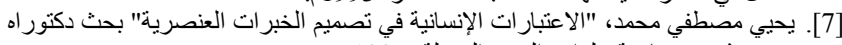

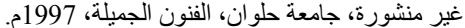

[8]. خلود حسن عزوز، تأثير الهوبة والثقافة علي سلوك الثرة الفرد داخل الفراغات المعمارية، رسالة

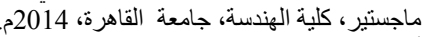

[9]. أحمد عمر ، هندسة القيمة، كمدخل لزيادة فاعلية تصميم نماذج إسكان متوسط، بحث ماجستير

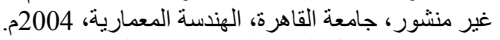

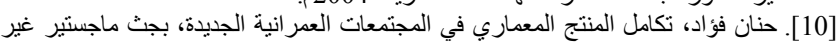

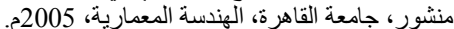

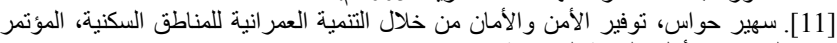

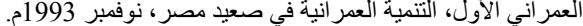

[12]. دمي توماس لازويل، الاعتبارات الإنسانية في التصميم المعماري، ترجمة د. د. عبد العزيز

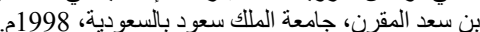

[13]. عبد الله فودة، دراسة الخصائص البيئية الثقافية في الفراغات الخارجية، بحث ماجستير غير منشور ، جامعة القاهرة، هندسة معمارية، 1991 1991م.

[14]. Lyman, Stan ford and Marvin B. Scott, "Territoriality - en eglected Socialgitcal Dimesion in People and Buildings, Edited by roport Gutman, New York, 1972.

[15]. عادل راضي، البيئة المعمارية و أثرها على سلوك الإنسان، ندوة التأثير المتبادل بين المأوي

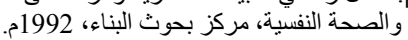

[16]. إيمان عطية، العوامل التي أثرت على شئل شكل وتطور المسقط الأفقي للمسكن من منظور

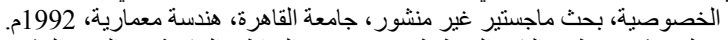

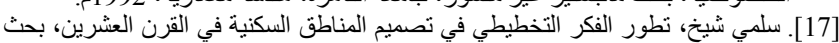

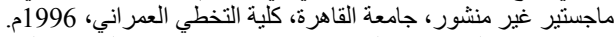

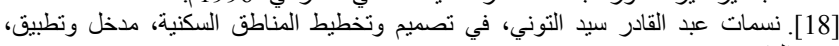

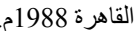

[19]. ايمان ريحان، مثابعة وتقييم مشروع نماذج الإسكان منخفض التكاليف، بحث ماجستير غير

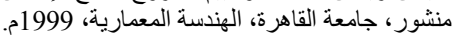

[20]. Serge Chemay, eff \& Clristopher alecander, Community and Privacy. Coublelay: and compang. Inc, New York, 1963.

[21]. سهير حتحوت، مضمون الخصوصية في البيئة العضوية، مجلة المهندس المصرية بالعدد

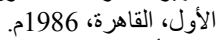

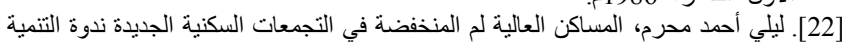
الإنسانية، الاجتماعية للمدن الجديدة من 7-10 أبريل فيل 1986، مركز البحوث الاجتماعية والجنائية.

[23]. رانية محمد علي طه، الثأثير المتبادل بين الواقع العمراني للمساكن والهوية الثقافية الثانية الاجتماعية للسكان، رسالة ماجستير ، جامعة النجاح الوطنية ، كلية الدراسات العليا، نابلس، فلسطين، 2010م.

[24]. محمد محمود أحمد، تهديف عمليات الإسكان في الأمارات المتحدة، بحث ماجستير غير

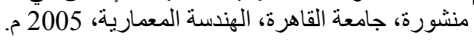

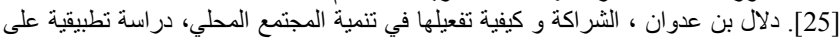

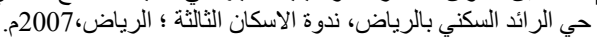

تدعي الحاجة لظهور ها من قبل اوجبها التغير الاجتماعي والثقافي الحاصل في الأسرة و المجتمع في ليبيا.

ومن خلال الجدول رقيلم (1) يتضح ان كلا من عناصر المدخل وحجرة

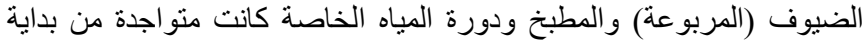

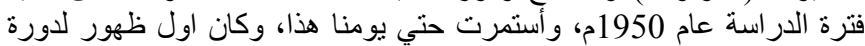

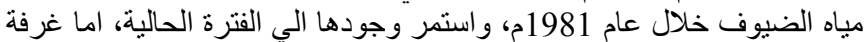

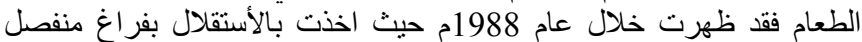

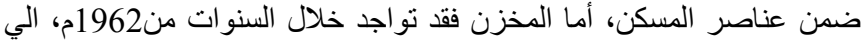

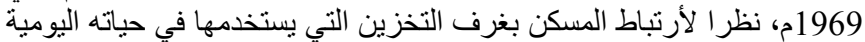

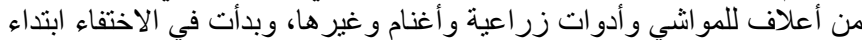

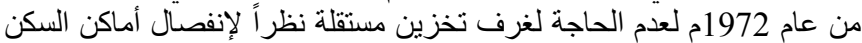

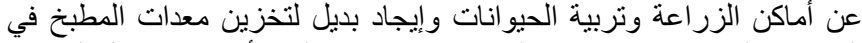

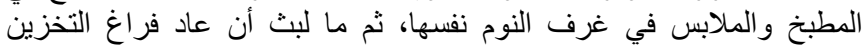

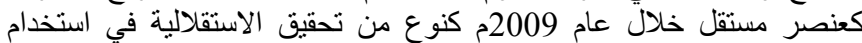

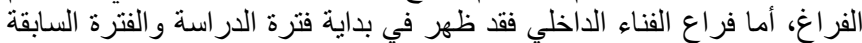

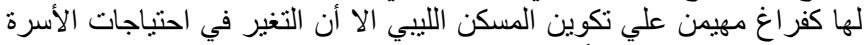

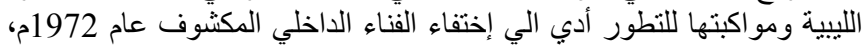

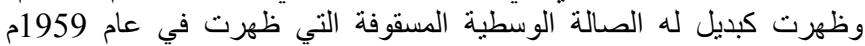

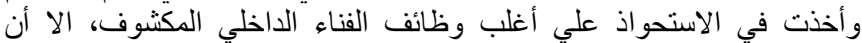

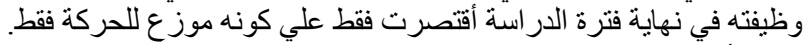

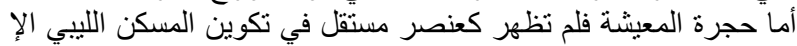

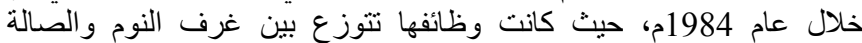

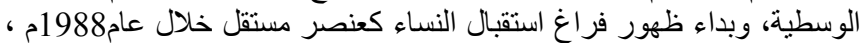

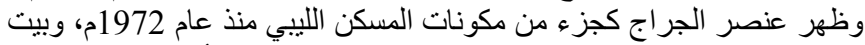

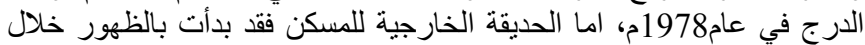

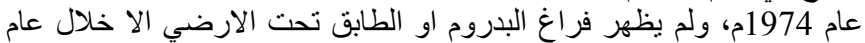

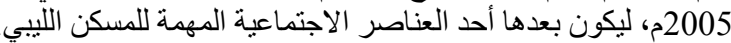

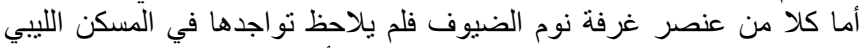

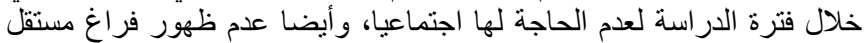

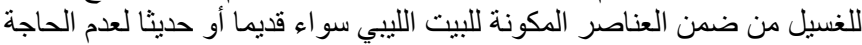

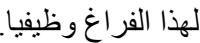

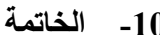

أن مفهوم الاحتياجات مفهوم ديناميكي نسبي ترتبط نوعيته بالزمان

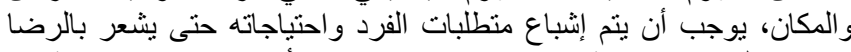

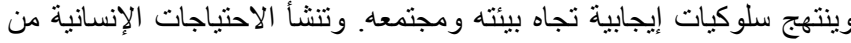
تفاعل دائم بين دوافع الإنسان الداخلية، وطريقة تحقيقها ومعطيات الإنيات البيأئة

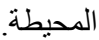

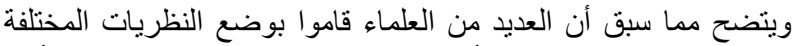

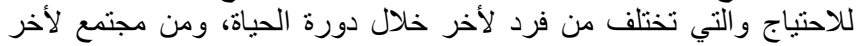

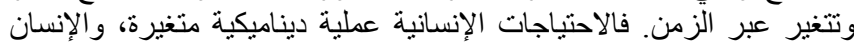

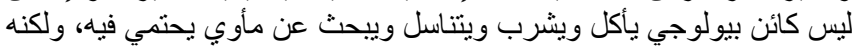
بالإضافة الي ذلك فهو كائن سيكولوجي بئنئن وئمل ويتفاعل ويفكر في في الترقي فإذا نوافرت للإنسان حاجته الأساسية فإن ذلك بعتبر مستوي للكفاف

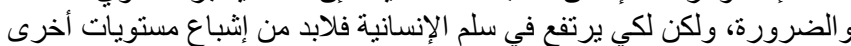

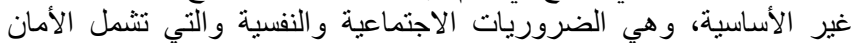

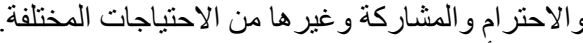

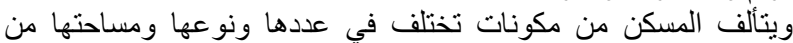

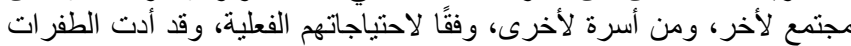

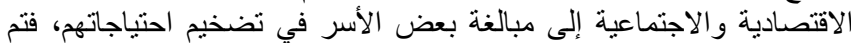

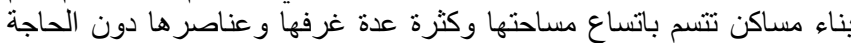

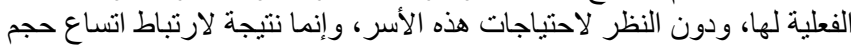

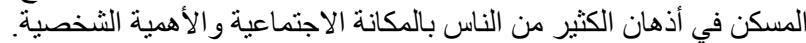

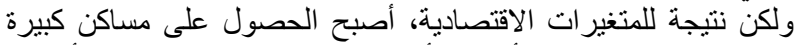

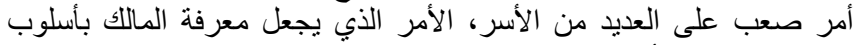

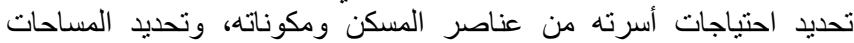

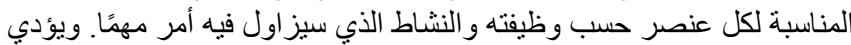

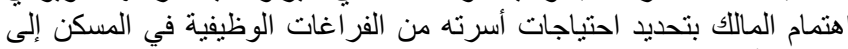

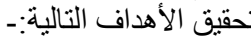


[29]. محسن قاسم، المشاكل الناتجة عن النمو السريع للمدن"، ندوة المأوي و التحضر، ديسمبر

[30]. عبد الرحمن سليمان الرشود، تأثير الأنماط السلوكية على تصميح جناح المعيشة في الرئي

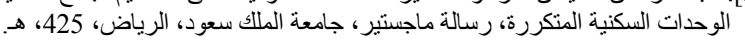

[31]. Sommer, Robert, Social Desing- creating Building with People in Mind, New Jersey, Prentice, Hall Inc. Engle wood cliffs, 1983.

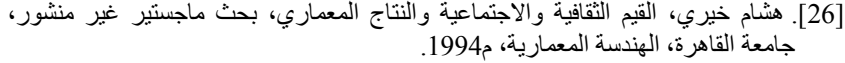

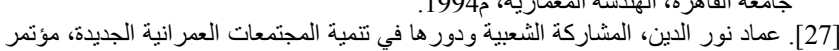

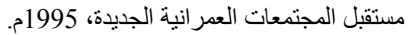

[28]. أحمد منير سليمان، الإسكات العمران والجيدة، التنمية المستديمة في الدول النامية دار الكتب الجامعية، بيروت، لبنان، 1996م أبنان 